\title{
NeuroImage
}

\section{Correlations of interictal FDG-PET metabolism and ictal SPECT perfusion changes in human temporal lobe epilepsy with hippocampal sclerosis}

\author{
N. Nelissen, ${ }^{\mathrm{a}, \mathrm{b}}$ W. Van Paesschen, ${ }^{\mathrm{a}, *}$ K. Baete, ${ }^{\mathrm{b}}$ K. Van Laere, ${ }^{\mathrm{b}}$ A. Palmini, ${ }^{\mathrm{a}, \mathrm{d}}$ \\ H. Van Billoen, ${ }^{\mathrm{c}}$ and P. Dupont ${ }^{\mathrm{b}}$ \\ a Department of Neurology, University Hospital Gasthuisberg, 49 Herestraat, 3000 Leuven, Belgium \\ ${ }^{\mathrm{b}}$ Department of Nuclear Medicine, University Hospital Gasthuisberg, Katholieke Universiteit Leuven, Belgium \\ ${ }^{\mathrm{c}}$ Department of Radiopharmacy, University Hospital Gasthuisberg, Katholieke Universiteit Leuven, Belgium \\ ${ }^{\mathrm{d}}$ Division of Neurology and Porte Alegre Epilepsy Surgery Program, Faculty of Medicine and Hospital São Lucas, \\ Pontificia Universidade Catolica do Rio Grande do Sul, Porto Alegre, Brazil
}

Received 18 January 2006; revised 7 April 2006; accepted 13 April 2006

Available online 9 June 2006

Background: The pathophysiological role of the extensive interictal cerebral hypometabolism in complex partial seizures (CPS) in refractory mesial temporal lobe epilepsy with hippocampal sclerosis (mTLE-HS) is poorly understood. Our aim was to study ictalinterictal SPECT perfusion versus interictal fluorodeoxyglucose (FDG)-PET metabolic patterns.

Methods: Eleven adults with refractory unilateral mTLE-HS, who were rendered seizure free after epilepsy surgery, were included. All had an interictal FDG-PET and an interictal and ictal perfusion SPECT scan. FDG-PET data were reconstructed using an anatomybased reconstruction algorithm, which corrected for partial volume effects, and analyzed semi-quantitatively after normalization to white matter activity. Using Statistical Parametric Mapping (SPM), we compared interictal metabolism of the patient group with a control group. We correlated metabolic with ictal perfusion changes in the patient group.

Results: Global cerebral grey matter glucose metabolism in patients was decreased $10-25 \%$ compared with control subjects. Interictal PET hypometabolism and ictal SPECT hypoperfusion were maximal in the ipsilateral frontal lobe. Ictal frontal lobe hypoperfusion was associated with crossed cerebellar diaschisis. The ipsilateral temporal lobe showed maximal ictal hyperperfusion and interictal hypometabolism, which was relatively mild compared with the degree of hypometabolism affecting the frontal lobes.

Conclusion: Interictal hypometabolism in mTLE-HS was greatest in the ipsilateral frontal lobe and represented a seizure-related dynamic process in view of further ictal decreases. Crossed cerebellar diaschisis suggested that there is a strong ipsilateral frontal lobe inhibition during CPS. We speculate that surround inhibition in the frontal lobe is a

\footnotetext{
* Corresponding author.

E-mail address: Wim.vanpaesschen@uz.kuleuven.ac.be (W. Van Paesschen).

Available online on ScienceDirect (www.sciencedirect.com).
}

dynamic defense mechanism against seizure propagation, and may be responsible for functional deficits observed in mTLE.

(c) 2006 Elsevier Inc. All rights reserved.

Keywords: Surround inhibition; Complex partial seizures; Hippocampal sclerosis; SPECT; Fluorodeoxyglucose PET

\section{Introduction}

In surgically treated mesial temporal lobe epilepsy with hippocampal sclerosis (mTLE-HS), interictal fluorodeoxyglucose (FDG)-PET hypometabolism has been reported to affect mainly the ipsilateral temporal lobe in $90-95 \%$ of cases, and to a much lesser extent also the ipsilateral basal frontal $(20-30 \%)$ and parietal lobes $(20-30 \%)$, thalamus $(60-70 \%)$ and basal ganglia $(40-50 \%)$ (Engel et al., 1990; Henry et al., 1990, 1993; Theodore et al., 1992; Wieser, 2004). Interpretation of FDG-PET images usually involves looking for asymmetries in metabolism, which may be bilateral in mTLE-HS in around $10-40 \%$ of cases, but greater on the side of HS (Wieser, 2004).

Ictal SPECT hyperperfusion has an excellent sensitivity for localizing seizure activity (Kaiboriboon et al., 2005; Kilpatrick et al., 1997; O'Brien et al., 1998; Shin et al., 2002; Zubal et al., 1995). Ictal hypoperfusion during temporal lobe complex partial seizures (CPS) in mTLE-HS affects various regions including the frontal and ipsilateral parietal lobes and may be due to a steal phenomenon, functional deactivation or ictal surround inhibition (Blumenfeld et al., 2004a; Lee et al., 2000; Menzel et al., 1998; Tae et al., 2005; Van Paesschen et al., 2003).

Bouilleret et al. (2002) studied the relationships between ictal SPECT hyperperfusion and interictal FDG-PET hypometabolism 
in TLE, reported a marked rate of concordance between the two, and suggested that seizures were generated and spread in interictally hypometabolic regions.

The aim of this study was to correlate interictal FDG-PET metabolism not only with ictal hyperperfusion but also ictal hypoperfusion in mTLE-HS. From the literature and our experience, our a priori hypothesis was that the epileptic temporal lobe would show maximal interictal hypometabolism and ictal hyperperfusion and the ipsilateral frontal lobe greatest ictal hypoperfusion with relatively preserved interictal metabolism. We were surprised to find the opposite interictal metabolic pattern, i.e., the frontal lobes showed the most severe interictal hypometabolism and ictal hypoperfusion, while the epileptic temporal lobe showed hypometabolism that was less severe than that of the frontal lobes and maximal ictal hyperperfusion.

\section{Materials and methods}

\section{Subjects}

We studied 11 patients (6 women) with a median age of 37 years (range: 32-51) who had refractory partial seizures with electroclinical features characteristic of MTLE, and MRI of the brain showing unilateral HS. They all underwent preoperative evaluation (see below), went to surgery, and were rendered seizure free with a median post-operative follow-up of 3 years (range: 26). Histopathology confirmed HS.

For preoperative evaluation, all patients underwent interictal and ictal EEG recordings, video analysis of seizures, neuropsychological assessment, and an MRI of the brain. The latter included T1- and T2-weighted sequences, fluid-attenuated inversion recovery (FLAIR) images and a magnetization prepared rapid gradient echo (MPRAGE) sequence on a 1.5-T Siemens Vision scanner. The MPRAGE images were used for segmentation (see below). In addition, all patients had interictal and ictal SPECT and subtraction ictal SPECT coregistered to MRI (SISCOM), and interictal FDGPET. At the time of FDG-PET, the patients were taking a median of 3 anti-epileptic drugs (AED) (range: 2-3). The median time between ictal SPECT and FDG-PET was 4 weeks (range: 1-22). Detailed clinical, neurophysiological, and structural imaging features are summarized in Table 1.

Twenty age- and gender-matched neurologically normal volunteers (11 women, median age of 29 years (range: 20-49)) were scanned using the same MRI and FDG-PET protocol as in the patient group. For these volunteers, informed consent had been obtained as approved by the local Ethics Committee.

\section{SPECT perfusion data acquisition}

All patients had an interictal and ictal SPECT study (Van Paesschen, 2004). Technetium-99m-ethyl cysteinate dimer $\left({ }^{99 \mathrm{~m}} \mathrm{Tc}-\right.$ ECD) $(600-1000 \mathrm{MBq})$ was used as tracer. The set-up for ictal SPECT injection has previously been described in detail (Van Paesschen et al., 2003; Vanbilloen et al., 1999). Ictal SPECT injection was performed during a CPS during video-EEG monitoring. All seizures were hypomotor, temporal lobe seizures. The duration of the seizure and the time of initiation of ictal SPECT injection were determined during analysis of the videoEEG recordings of the CPS. Seizure onset was defined on clinical or EEG grounds, whichever was first. Ictal SPECT injection was

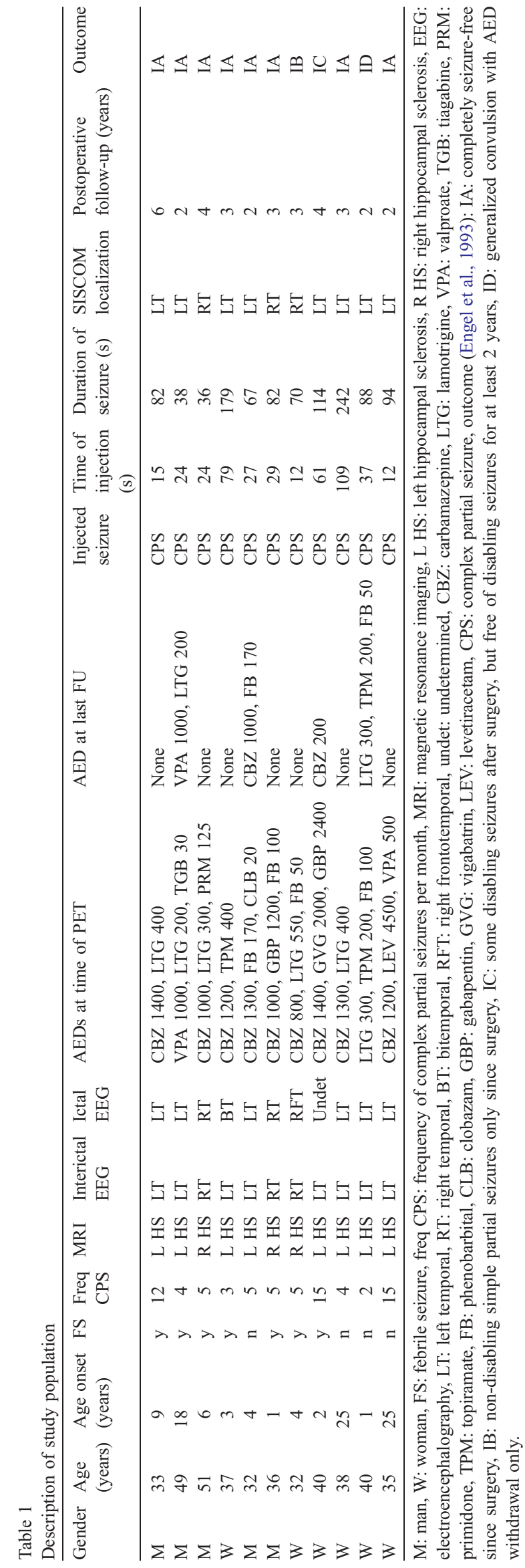


given at a median of $27 \mathrm{~s}$ after seizure onset (range: 12-109). The median duration of the injected seizure was $82 \mathrm{~s}$ (range: $36-242$ ). The median duration of the seizure after initiation of injection was 53 s (range: 12-133). Injection of the tracer for the interictal SPECT was performed with surface EEG monitoring. Patients were injected in the EEG suite, with eyes open in a dimly lit and quiet environment. SPECT imaging commenced within $1 \mathrm{~h}$ of tracer injection and acquisition and reconstruction of images was performed according to our standard protocol (see Van Paesschen et al., 2003, for details).

\section{PET metabolic data acquisition}

Using a Siemens HR+ high-resolution PET scanner, an FDGPET scan was acquired after injection of $150 \mathrm{MBq}$ FDG in the nuclear medicine department under continuous EEG monitoring (see Baete et al., 2004a for details of the acquisition).

\section{Image processing}

Images of patients with right HS were flipped in order to align the epileptogenic zone on the same side, i.e., the ipsilateral side was on the left.

\section{Perfusion data}

The two SPECT scans from each subject were coregistered using mutual information (Maes et al., 1997) and the mean image was calculated. The ictal and interictal SPECT images were normalized for global counts and smoothed with a 3D-isotropic Gaussian kernel of 16-mm full width at half maximum (FWHM). Then a voxelwise subtraction between these images was performed: difference (DIF) = ictal perfusion SPECT - interictal perfusion SPECT. This latter image was transformed into a $z$ score image as follows: $z_{\text {SPECT }}=(\mathrm{DIF}-$ mean $(\mathrm{DIF})) / \mathrm{SD}(\mathrm{DIF})$ where mean (DIF) is the mean difference, and SD is the standard deviation in DIF calculated across all voxels (limited to the brain) in each individual patient.

\section{Metabolic data}

The T1-weighted MRI scan (MPRAGE) was segmented (Van Leemput et al., 1999) to yield grey matter (GM), white matter (WM) and cerebrospinal fluid (CSF) probability maps. FDG-PET data were reconstructed using the anatomy-based maximum a posteriori iterative reconstruction (AMAP) algorithm (Baete et al., 2004a,b). PET images were normalized using the coregistered binarized WM map as reference region. In WM, changes in metabolism caused by AEDs are - to the best of our knowledge not reported, in contrast with changes in GM (Gaillard et al., 1996; Theodore, 1988). To test the validity of this WM normalization, we compared the distributions of the voxel intensities in the GM, respectively WM, of patients with those of normal controls in the same tissue classes. Since we used exactly the same PET imaging protocol and a fixed dose in every subject, variations in distribution were expected to be similar for both groups. Using a one-sided Mann-Whitney $U$ test to compare the median values of the intensity in GM and WM, respectively, between patients and normal controls, we found a significant difference for GM ( $P=$ $0.038)$ but not for WM ( $P=0.296)$, which is in agreement with reports in the literature (Gaillard et al., 1996; Theodore, 1988). We, therefore, considered WM normalization a better solution than normalization for global counts.
The PET images were warped (using linear and non-linear components) into the Montreal Neurological Institute (MNI) standard space using SPM2. The corresponding transformation was also applied to the ictal and interictal SPECT perfusion images and to the $z_{\text {SPECT }}$ images (all these images were first coregistered to the PET image using the transformation of the coregistration between the mean of the ictal and interictal image and the PET image using mutual information). The warped PET images were then smoothed by convolution with a 3D-isotropic Gaussian kernel of 16-mm FWHM.

For each individual patient, we calculated a $z$ score image as follows: $z_{\mathrm{PET}}=\left(\mathrm{PET}_{\text {patient }}-\operatorname{mean}\left(\mathrm{PET}_{\text {controls }}\right)\right) / \mathrm{SD}\left(\mathrm{PET}_{\text {controls }}\right)$ in which PET $_{\text {patient }}$ is the normalized and smoothed PET image of a patient, and mean and SD are the mean and standard deviation images across the normalized and smoothed PET images of the whole control group.

\section{Statistical parametric mapping}

Analysis was carried out using Statistical Parametric Mapping (SPM) software (version SPM2, Wellcome Department of Cognitive Neurology, London, UK. http://www.fil.ion.ucl.ac.uk/spm), implemented in MATLAB (Matlab 6.5. The MathWorks, Inc., Sherborn, MA, USA. http://www.mathworks.com/products/matlab). Statistical analysis was done using STATISTICA (version 6, StatsSoft, Inc. www.statsoft.com).

\section{Perfusion data}

A paired $t$ test was performed in each voxel using the framework of the general linear model (Friston, 1996; Worsley et al., 1992). Two contrasts (ictal versus interictal SPECT and the reverse) were tested (fixed effect model) and for each contrast the resulting set of voxel values constituted a statistical parametric map of the $t$ statistic $\operatorname{SPM}\{t\}$. The significance threshold was set at $P_{\text {uncor }}<0.001$ for peak height, and an extent threshold of 20 voxels was used, because similar results were obtained as in our previous analysis (Van Paesschen et al., 2003) in which we used a threshold of $P_{\text {cor }}<0.05$ (corrected for multiple comparisons) in a larger group of patients with mTLE-HS. Perfusion changes were determined in every patient and in each brain voxel as the percentage change with respect to the interictal perfusion, using the normalized and smoothed SPECT data. A mean image mean $_{\Delta \text { perfusion }}$ of the perfusion changes across all patients was calculated.

\section{Metabolic data}

A two-sample $t$ test was performed in each voxel between the patient group and the group of normal controls using the smoothed normalized PET data. Two contrasts were tested: patients minus controls (showing voxels with hypermetabolism in patients compared with normal controls) and controls minus patients (showing voxels with hypometabolism in the patients compared with controls). The same thresholds as for the perfusion data were chosen. For each patient, the changes in metabolism were calculated as percentage change with respect to the mean image of the normalized and smoothed PET images in all controls.

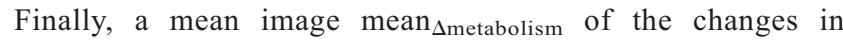
metabolism was calculated across all patients.

To test for asymmetry of metabolism in patients, we compared the smoothed normalized PET images of patients with their left/ right flipped counterpart using a paired $t$ test in SPM. 
In a sphere (radius $8 \mathrm{~mm}$ ) around the coordinate showing a local maximum in the $T$-map (see SPM analysis), we calculated the maximal change in the mean ${ }_{\Delta \text { perfusion }}$ respectively mean ${ }_{\Delta \text { metabolism. }}$. In the same sphere, we calculated the maximal number of subjects showing a $z_{\mathrm{PET}}>1, z_{\mathrm{PET}}<-1, z_{\mathrm{SPECT}}>1$ or $z_{\mathrm{SPECT}}<-1$.

\section{Composite images}

The individual $z_{\text {SPECT }}$ maps and $z_{\text {PET }}$ maps of all patients were converted into 5 new composite images (Hogan et al., 2004; Kaiboriboon et al., 2005), giving for every voxel the number of patients with (1) $z_{\mathrm{PET}}$ values $<-1$ (interictal hypometabolism), (2) $z_{\text {SPECT }}$ values $>1$ (ictal hyperperfusion) or (3) $z_{\text {SPECT }}$ values $<-1$ (ictal hypoperfusion), (4) the combination of $z_{\mathrm{PET}}$ values $<-1$ and $z_{\text {SPECT }}$ values $>1$ (interictal hypometabolism and ictal hyperperfusion), and (5) the combination of $z_{\mathrm{PET}}$ values $<-1$ and $z_{\text {SPECT }}$ values $<-1$ (interictal hypometabolism and ictal hypoperfusion).

\section{Results}

\section{SPECT data}

SPM analysis of the comparison of ictal and interictal perfusion in the group of patients revealed that ictal SPECT hyperperfusion (Table 2 and Figs. 1A, B) was maximal in the temporal lobe with HS, from where seizures were shown to originate, the ipsilateral

Table 2

Ictal SPECT hyperperfusion

\begin{tabular}{|c|c|c|c|c|c|c|c|c|c|c|}
\hline & \multirow{2}{*}{\multicolumn{2}{|c|}{$\frac{\text { Ictal perfusion }}{\text { w.r.t. interictal perfusion }}$}} & \multirow{2}{*}{\multicolumn{2}{|c|}{$\frac{\text { Interictal metabolism }}{\text { w.r.t. control group }}$}} \\
\hline \multicolumn{7}{|c|}{ Ictal hyperperfusion } & & & & \\
\hline Region & Side & $x$ & $y$ & $z$ & $\begin{array}{l}\text { Tentative anatomical } \\
\text { localization }\end{array}$ & $T$ value & \%Difference & No. of patients & $\%$ Difference & No. of patients \\
\hline \multicolumn{11}{|c|}{ Mesial temporal } \\
\hline & \multirow[t]{3}{*}{ IL } & -22 & -30 & -16 & Parahippoc g & 7.01 & 18.3 & 9 & -14.0 & 7 \\
\hline & & -24 & -40 & -8 & Hippoc/parahippoc g/post temp & 7.15 & 16.3 & 9 & -12.0 & 7 \\
\hline & & -22 & 4 & -28 & Uncus/amygdala/inf front $\mathrm{g}$ & 14.22 & 25.7 & 11 & -7.6 & 5 \\
\hline \multicolumn{11}{|c|}{ Lateral temporal } \\
\hline & \multirow[t]{5}{*}{$\mathrm{IL}$} & -32 & 20 & -42 & Sup temp g & 12.83 & 24.3 & 11 & -15.7 & 8 \\
\hline & & -54 & 16 & -28 & Sup temp $\mathrm{g}$ & 15.42 & 29.0 & 11 & -16.2 & 8 \\
\hline & & -42 & 10 & -44 & Sup temp g & 12.54 & 26.3 & 11 & -17.5 & 8 \\
\hline & & -62 & 6 & -24 & Sup/middle temp g & 13.15 & 27.5 & 10 & -14.8 & 7 \\
\hline & & -46 & -8 & -52 & Middle temp g & 14.13 & 17.8 & 8 & -12.5 & 7 \\
\hline \multicolumn{11}{|l|}{ Frontal } \\
\hline & \multirow[t]{2}{*}{ IL } & -34 & -8 & -14 & Insula/front & 11.93 & 22.4 & 11 & -10.3 & 7 \\
\hline & & -24 & 22 & -12 & Inf front $\mathrm{g}$ & 5.05 & 10.5 & 8 & -12.0 & 5 \\
\hline \multicolumn{11}{|l|}{ Parietal } \\
\hline & IL & -32 & -14 & 26 & Pre/postcentral g & 4.63 & 8.5 & 4 & -11.5 & 8 \\
\hline \multicolumn{11}{|c|}{ Occipital } \\
\hline & \multirow[t]{4}{*}{$\mathrm{IL}$} & -20 & -82 & 0 & Lingual g & 6.72 & 9.1 & 8 & -11.1 & 7 \\
\hline & & -12 & -90 & 14 & Middle occip g/cuneus & 5.67 & 11.4 & 9 & -9.0 & 6 \\
\hline & & -4 & -92 & 6 & Cuneus & 5.88 & 11.8 & 10 & -11.1 & 7 \\
\hline & & -12 & -98 & 32 & Cuneus & 6.13 & 11.4 & 7 & -9.3 & 5 \\
\hline & \multirow[t]{5}{*}{$\mathrm{CL}$} & 24 & -74 & -2 & Lingual $\mathrm{g} /$ cingulate $\mathrm{g} / \mathrm{post}$ temp & 6.38 & 11.1 & 8 & -8.6 & 7 \\
\hline & & 34 & -82 & -4 & Middle occip g & 6.49 & 10.0 & 7 & -9.7 & 6 \\
\hline & & 14 & -82 & 12 & Cuneus & 5.41 & 11.5 & 10 & -10.4 & 7 \\
\hline & & 42 & -94 & 24 & Sup occip g & 6.49 & 11.0 & 5 & -12.8 & 7 \\
\hline & & 44 & -98 & 10 & Middle occip g & 5.41 & 11.0 & 4 & -10.5 & 6 \\
\hline \multicolumn{11}{|c|}{ Cerebellum } \\
\hline & midline & 0 & -60 & -18 & Post cerebellum & 8.60 & 8.5 & 9 & -4.3 & 5 \\
\hline & IL & -32 & -32 & -38 & Ant cerebellum & 4.24 & 12.0 & 5 & -12.3 & 7 \\
\hline & \multirow[t]{4}{*}{$\mathrm{CL}$} & 6 & -44 & -14 & Ant cerebellum & 10.48 & 7.6 & 6 & -6.3 & 6 \\
\hline & & 4 & -48 & -28 & Ant cerebellum & 9.72 & 8.8 & 7 & -5.1 & 3 \\
\hline & & 2 & -58 & -32 & Ant cerebellum & 8.38 & 9.0 & 9 & -7.6 & 5 \\
\hline & & 16 & -40 & -16 & Ant cerebellum/occipitotemp & 7.58 & 6.9 & 5 & -8.5 & 7 \\
\hline
\end{tabular}

SPM analysis showing the local maxima after thresholding at $P<0.001$ (coordinates significant at $P<0.05$ corrected for multiple comparisons are indicated in bold). For each coordinate, the maximal change (\%difference) of perfusion and metabolism as well as the maximum number of patients showing this pattern in the individual $z$ map (thresholded at $|z|>1$ ) within a sphere with a radius of $8 \mathrm{~mm}$ is given (see Materials and methods). $x, y, z$ coordinates in mm in MNI space with respect to the anterior commissure (at the level of the anterior commissure: $x=0$ ( \pm contralateral/ipsilateral), $y=0$ ( \pm anterior/posterior), $z=0$ ( \pm superior/inferior)). Abbreviations: ant: anterior; post: posterior; g: gyrus; occip: occipital; sup: superior; inf: inferior; temp: temporal; front: frontal; hippoc: hippocampus. 

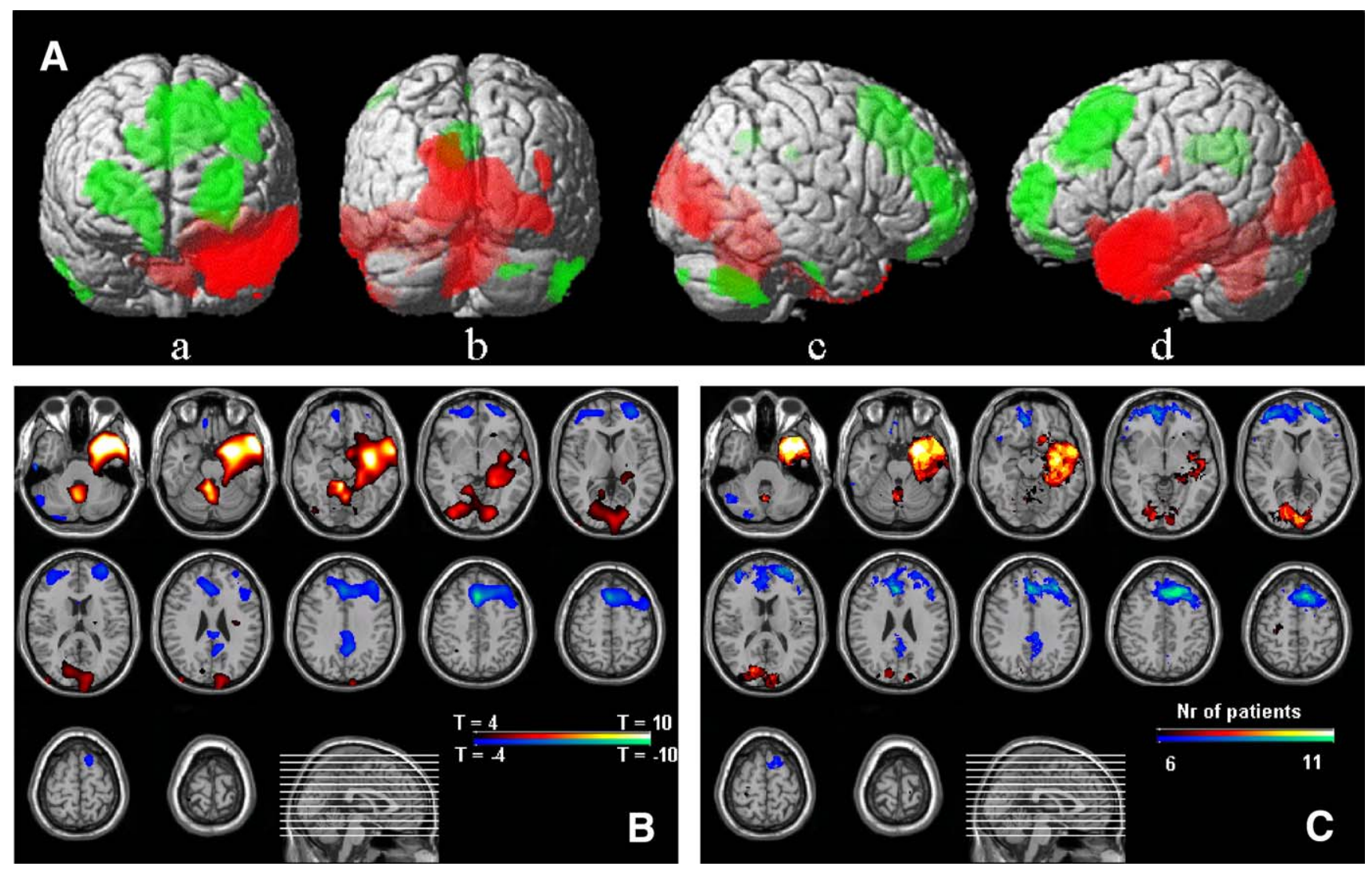

Fig. 1. Ictal SPECT perfusion changes during CPS in mTLE-HS. (A) Brain regions with significant ictal cerebral hyperperfusion (red) and hypoperfusion (green) (uncorrected $P$ value $<0.001$ ) during CPS in 11 patients with HS are shown on a surface rendering of an MRI of the brain. (a) Anterior view, (b) posterior view, (c) contralateral view, (d) ipsilateral view. (B) SPM $t$ map for the analysis of ictal versus interictal perfusion SPECT. Hyperperfusion is in yellow/red, hypoperfusion in blue/green. (C) Composite SPECT images of hyperperfusion (red/yellow) and hypoperfusion (blue/green) (see Materials and methods). Color scale indicates the number of patients (maximum 11) with a given voxel surviving the threshold of $|z|>1$. In both panels B and C, the results were projected on the MRI of a single subject available in SPM2, and right side of the image is ipsilateral to the seizure focus.

inferior frontal lobe and the contralateral anterior cerebellum. Milder degrees of hyperperfusion were also seen in the ipsilateral insula and parietal lobe, in both occipital lobes and parts of the cerebellum. Analysis of the individual $z_{\text {SPECT }}$ maps (thresholded at $z_{\text {SPECT }}>1$ ) revealed (Table 2, Fig. 1C) that the ictal hyperperfusion was present in all patients in the ipsilateral temporal lobe and insula. Bilateral occipital hyperperfusion was seen in 10 patients, contralateral cerebellar hyperperfusion in 9, ipsilateral cerebellar hyperperfusion in 5 and the ipsilateral parietal lobe hyperperfusion in only 4 patients.

Ictal SPECT hypoperfusion (Table 3 and Figs. 1A, B), on the other hand, was maximal in the frontal lobes, in the ipsilateral parietal lobe and the contralateral cerebellum, and in a small region in the contralateral temporal lobe. On the thresholded individual $z_{\text {SPECT }}$ map (Table 3, Fig. 1C), hypoperfusion in the frontal lobes was present in all patients, although not always bilateral, in the contralateral cerebellum in 10 , in the ipsilateral parietal lobe in 8 , and the contralateral temporal lobe in only 4 patients.

\section{PET data}

On visual assessment of the FDG-PET images, the metabolism was asymmetric in the temporal lobes, and the epileptic temporal lobe was considered the most hypometabolic region in the brain in all cases (Fig. 2A). Comparing patients with control subjects, however, hypometabolism in extratemporal regions, most notably the frontal lobes, was greater than in the temporal lobes (Figs. 2C and D).

On quantitative assessment, the asymmetry in metabolism was significant only in the temporal lobes (Fig. 2B). Interictal hypometabolism in the patient group compared with the control group (Table 4 and Figs. 3A and B) was most significant in the ipsilateral frontal lobe. Milder degrees of hypometabolism were seen in the contralateral frontal lobe, both parietal and lateral temporal lobes and the thalamus, the ipsilateral mesial temporal and occipital lobe, and the cerebellum. The ipsilateral mesial temporal lobe was one of the least hypometabolic regions in the brain, i.e., metabolism was decreased in this region, but not as much as in other areas. Analysis of the individual $\mathrm{Z}_{\mathrm{PET}}$ maps (thresholded at $z_{\text {PET }}<-1$ ) showed that hypometabolism was present in the frontal lobes in 10 patients, in the ipsilateral temporal lobe in 9 , in the parietal lobes in 9, in the ipsilateral occipital lobe in 8 , in the cerebellum in 9 and in the thalami in 7 (Fig. 3C).

There were no voxels showing significant interictal hypermetabolism in the patient group compared with the control group.

\section{PET and SPECT data combined}

The combination of the perfusion and metabolic data (Figs. 4A, B) showed that within the large area of hypometabolism in the 
Table 3

Ictal SPECT hypoperfusion

\begin{tabular}{|c|c|c|c|c|c|c|c|c|c|c|}
\hline \multicolumn{7}{|c|}{ Ictal hypoperfusion } & \multicolumn{2}{|c|}{ Ictal perfusion } & \multirow{2}{*}{\multicolumn{2}{|c|}{$\frac{\text { Interictal metabolism }}{\text { w.r.t. control group }}$}} \\
\hline & & & & & & & \multicolumn{2}{|c|}{ w.r.t. interictal perfusion } & & \\
\hline Region & Side & $x$ & $y$ & $z$ & $\begin{array}{l}\text { Tentative anatomical } \\
\text { localization }\end{array}$ & $\begin{array}{l}T \\
\text { value }\end{array}$ & $\%$ Difference & $\begin{array}{l}\text { No. of } \\
\text { patients }\end{array}$ & \%Difference & $\begin{array}{l}\text { No. of } \\
\text { patients }\end{array}$ \\
\hline \multicolumn{11}{|c|}{ Lateral temporal } \\
\hline & $\mathrm{CL}$ & 60 & -18 & -34 & Inf temp $g$ & 7.15 & -5.6 & 4 & -11.4 & 6 \\
\hline \multicolumn{11}{|l|}{ Frontal } \\
\hline & Midline & 0 & 20 & 48 & Sup front $g$ & 10.25 & -11.2 & 11 & -20.6 & 10 \\
\hline & IL & -38 & 34 & 42 & Middle front $\mathrm{g}$ & 6.58 & -12.8 & 10 & -15.3 & 7 \\
\hline & & -48 & 10 & 52 & Middle front $\mathrm{g}$ & 5.54 & -9.8 & 8 & -17.2 & 8 \\
\hline & & -28 & 56 & 4 & Sup front $g$ & 6.50 & -12.8 & 9 & -17.7 & 8 \\
\hline & $\mathrm{CL}$ & 14 & 56 & -6 & Medial front $g$ & 5.62 & -11.2 & 9 & -12.1 & 7 \\
\hline & & 34 & 52 & 12 & Middle/sup frontal $g$ & 4.96 & -11.2 & 9 & -14.7 & 8 \\
\hline & & 38 & 44 & 16 & Middle front $\mathrm{g}$ & 4.98 & -10.6 & 9 & -15.8 & 8 \\
\hline & & 10 & 42 & -22 & Medial front $\mathrm{g}$ & 4.83 & -9.5 & 8 & -10.2 & 4 \\
\hline \multicolumn{11}{|l|}{ Parietal } \\
\hline & IL & -4 & -30 & 30 & Post cingulate $g$ & 6.40 & -8.8 & 8 & -15.5 & 8 \\
\hline & & -10 & -48 & 32 & Post cingulate $\mathrm{g}$ & 5.96 & -9.1 & 7 & -16.0 & 8 \\
\hline & & -2 & -52 & 38 & Precuneus & 6.10 & -8.9 & 8 & -16.1 & 8 \\
\hline \multicolumn{11}{|c|}{ Cerebellum } \\
\hline & $\mathrm{CL}$ & 54 & -62 & -38 & Post cerebellum & 5.30 & -12.5 & 10 & -8.1 & 7 \\
\hline & & 22 & -88 & -36 & Post cerebellum & 4.45 & -8.4 & 7 & -11.8 & 7 \\
\hline
\end{tabular}

SPM analysis showing the local maxima after thresholding at $P<0.001$.

Same conventions as in Table 2.

patient group (Figs. 3A, B) two separate regions could be statistically singled out: (1) the ipsilateral temporal lobe with HS showing ictal hyperperfusion and (2) a larger region encompassing the frontal lobes at the midline and extending towards the ipsilateral side showing ictal hypoperfusion. These regions were significant (uncorrected $P$ value $<0.001$ ) both in perfusion and metabolic changes. On an individual basis, we found the same areas with significant perfusion and metabolic changes in about half of the patients (Figs. 4C, D).

\section{Discussion}

The most important findings of our study were that interictal hypometabolism was greatest in the ipsilateral frontal lobe, with further decreases during CPS, and that interictal ipsilateral temporal lobe hypometabolism was relatively mild, compared with the degree of hypometabolism affecting the frontal lobes, with maximal ictal increases.

Three methodological issues are important to understand our findings. First, in our patients with mTLE-HS, who were taking on average three AEDs in high dosage, the interictal cerebral glucose metabolism was decreased in the range of $10-25 \%$ compared with normal control subjects. This is in agreement with quantitative FDG-PET studies (Gaillard et al., 1996; Theodore, 1988), that showed that AEDs cause reductions in metabolism from 10 to $30 \%$. Since quantitative FDG-PET studies using arterial sampling were not possible in our clinical setting, we had to rely on a semiquantitative analysis of PET data. Crucial in our methodology was WM normalization (Baete et al., 2004a,b). We did not find any evidence in the literature to suggest that WM metabolism was decreased in patients with epilepsy taking multiple AEDs, nor did we find any significant difference in WM metabolism between our patients and controls, although the sample size was small. Since GM in patients was severely hypometabolic compared with controls, normalization for global counts would have caused regionally spuriously increased metabolic values, which we found (data not shown).

Secondly, neocortical (Liu et al., 2003) and ipsilateral thalamic (Bonilha et al., 2005) atrophy commonly develops in chronic TLE. Therefore, correction for partial volume effect, as in our study (Baete et al., 2004a,b), was important for a valid comparison of our patient with the control group.

Thirdly, a voxel-based comparison of the group of patients versus a control group allowed us to observe a new pattern of hypometabolism in mTLE-HS, affecting most severely frontal and parietal lobes, ipsilateral more than contralateral. Most PET studies relied on asymmetry indices between regions of interest in homologous brain regions, and found the largest asymmetry in the temporal lobes (Engel et al., 1990; Henry et al., 1990, 1993; Rubin et al., 1995; Theodore et al., 1992; Van Bogaert et al., 2000), as we found. The methodology of interhemispheric asymmetry indices has failed to pick up the severe hypometabolism in frontoparietal regions in mTLE-HS in view of the bilateral reductions. Interestingly, Tae et al. (2005) reported a similar pattern of interictal SPECT hypoperfusion in bilateral frontoparietal lobes in patients with mTLE-HS compared with normal control subjects using SPM. It should be stressed that the visual readings of the PET scans, which were used in the presurgical evaluation, showed ipsilateral temporal lobe hypometabolism in all our patients. The extensive frontal lobe hypometabolism, however, was missed on visual inspection in all our patients and was only detected using our new methodology, as can be seen in Fig. 2. Our findings should have 

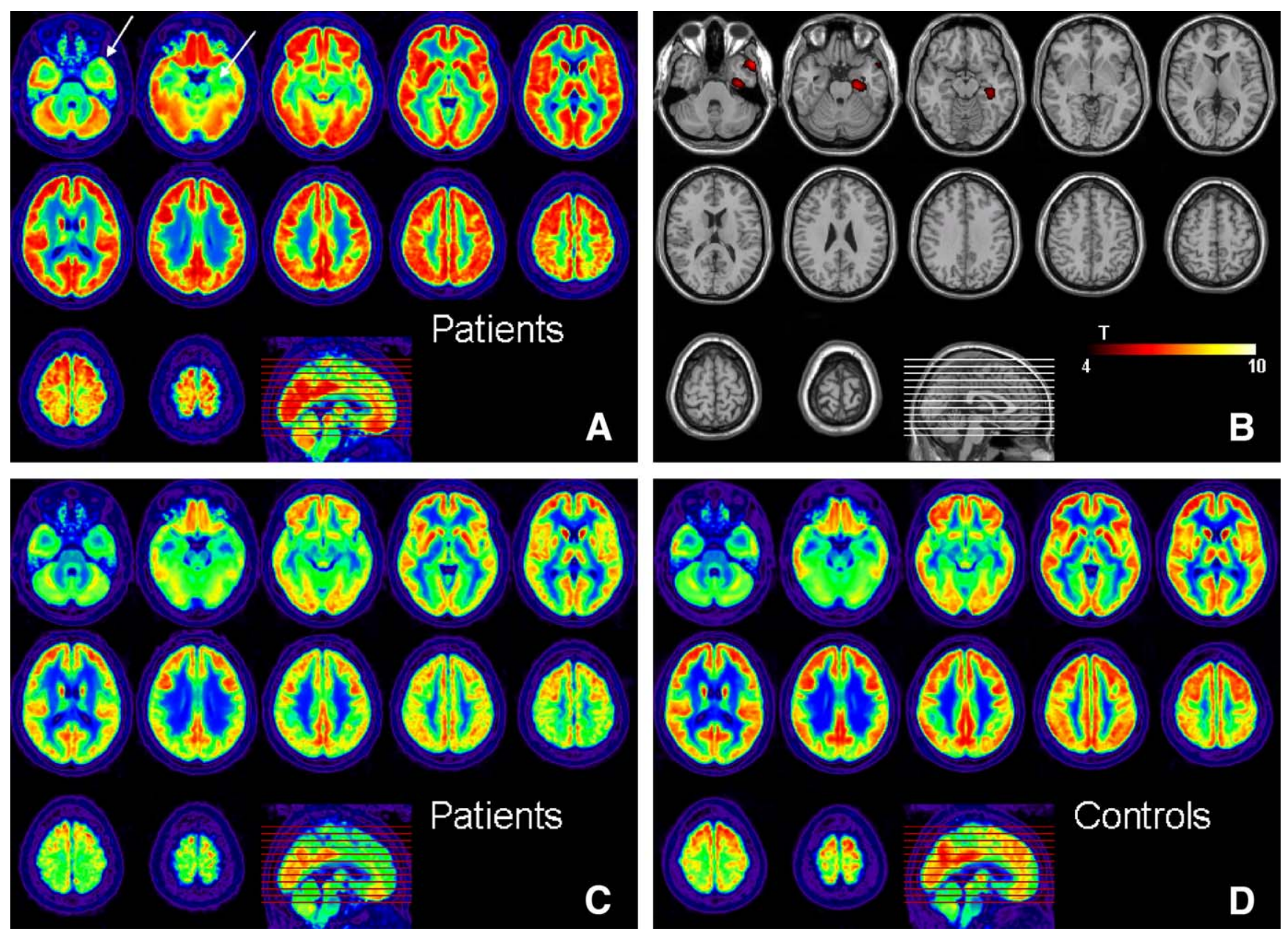

Fig. 2. Visual assessment of FDG-PET images. (A) Visual assessment of the mean image of the normalized FDG-PET across all patients, using its own color table, showed that the temporal lobe with HS (white arrows) was more hypometabolic than the contralateral side, and appeared the most hypometabolic region in the brain. (B) SPM $t$ map (uncorrected $P$ value $<0.001$ ) shown on the MRI of a single subject in MNI space (provided with SPM2) confirmed that a significant asymmetry in interhemispheric metabolism was only found in the temporal lobes. (C and D) Visual assessment of the mean images of the normalized FDG-PET across all patients (C) and controls (D), displayed using the same color table, showed a striking hypometabolism in the fronto-parietal lobes in patients compared with control subjects. The hypometabolism in the epileptic temporal lobe, on the other hand, was less striking than the changes in the extratemporal regions.

immediate implications for the clinical reporting of FDG-PET scans of patients with partial epilepsy.

Further ictal decreases in perfusion in the frontal lobe that was already severely hypometabolic interictally indicate that these functional changes represent a seizure-related dynamic process. In the literature, we found several lines of evidence supporting this observation. Witte et al. (1994) described a patient who had a partial seizure during a PET scan. The transition from interictal to ictal activity in this patient was accompanied by the development of a hypermetabolic epileptic focus and the dynamic enlargement of the surrounding hypometabolism. The pattern of interictal hypometabolism in FDG-PET scans has been reported to be related to ictal discharge generation and spread pathways (Chassoux et al., 2004) and to reflect prior seizure types in patients with mTLE (Savic et al., 1997). The degree of hypometabolism also correlated with the number of seizures (Matheja et al., 2001). We reported an inverse association between ipsilateral temporal lobe hyperperfusion and ipsilateral frontal lobe hypoperfusion (Van Paesschen et al., 2003). Finally, ipsilateral frontal lobe hypometabolism may resolve in patients with refractory mTLE who were rendered seizure free after epilepsy surgery (Hajek et al., 1994; Joo et al., 2005; Spanaki et al., 2000).

Crossed cerebellar diaschisis during CPS indicate that neuronal activity in the ipsilateral frontal lobe is decreased. In a study of crossed cerebellar diaschisis, Gold and Lauritzen (2002) reported that a decrease of cerebellar perfusion of around $10-15 \%$, as in our study, was only seen with structural or total functional ablation of the frontal lobe. We, therefore, postulate that crossed cerebellar diaschisis during CPS is due to a severe decrease in frontal lobe neuronal activity, probably due to inhibition. This hypothesis of frontal lobe inhibition is supported by depth EEG studies of the frontal lobes during CPS in mTLE, which showed ictal EEG slowing in these regions, consistent with inhibition (Blumenfeld et al., 2004b). Also, in an animal model of epilepsy, the combination of in vivo optical imaging and EEG has shown a dynamic interplay between an increased optical signal, that correlated with EEG epileptic activity in an epileptic focus, and a decreased optical 
Table 4

Interictal FDG-PET hypometabolism

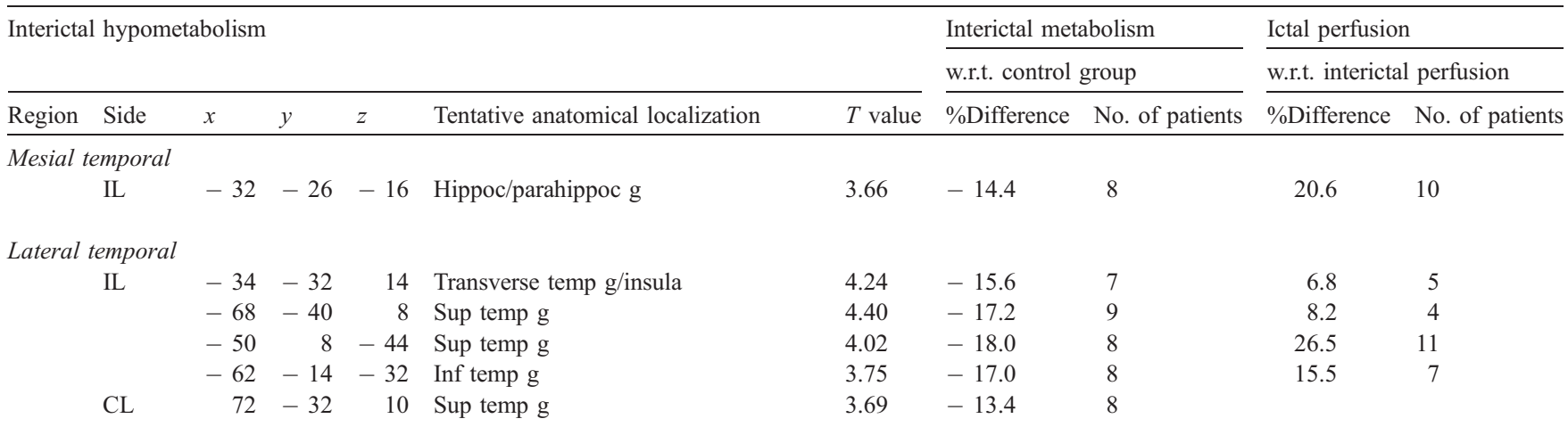

Frontal

\begin{tabular}{|c|c|c|c|c|c|c|c|c|c|}
\hline Midline & 0 & 30 & 38 & Sup front $\mathrm{g}$ & 4.55 & -19.1 & 9 & -10.7 & 11 \\
\hline \multirow[t]{12}{*}{ IL } & -44 & 58 & 2 & Middle front $\mathrm{g}$ & 4.83 & -22.6 & 9 & -8.2 & 4 \\
\hline & -24 & 46 & 54 & Sup front $\mathrm{g}$ & 4.91 & -17.8 & 8 & -10.6 & 3 \\
\hline & -54 & 32 & 16 & Inf front $\mathrm{g}$ & 3.89 & -15.6 & 8 & -8.3 & 7 \\
\hline & -16 & 30 & 46 & Medial/sup front $\mathrm{g}$ & 4.62 & -17.7 & 9 & -13.5 & 11 \\
\hline & -52 & 30 & 2 & Inf front $\mathrm{g}$ & 3.74 & -15.8 & 7 & -9.1 & 6 \\
\hline & -48 & 20 & 0 & Inf front $\mathrm{g}$ & 3.78 & -15.67 & 7 & -8.2 & 6 \\
\hline & -56 & 14 & 38 & Middle front $g$ & 4.53 & -20.7 & 9 & -9.0 & 7 \\
\hline & -18 & 12 & 76 & Sup front $\mathrm{g}$ & 4.68 & -22.1 & 10 & -8.6 & 5 \\
\hline & -4 & 10 & 52 & Medial front $\mathrm{g}$ & 4.95 & -20.8 & 10 & -9.7 & 9 \\
\hline & -36 & 8 & 64 & Middle/sup front $\mathrm{g}$ & 4.38 & -19.5 & 10 & -9.3 & 6 \\
\hline & -16 & 0 & 76 & Sup front $\mathrm{g}$ & 4.81 & -22.1 & 10 & -6.2 & 5 \\
\hline & -24 & -28 & 70 & Pre/postcentral g & 3.73 & -16.3 & 9 & 3.0 & 7 \\
\hline \multirow[t]{9}{*}{$\mathrm{CL}$} & 30 & 36 & 50 & Middle/sup front $\mathrm{g}$ & 4.25 & -16.1 & 9 & 5.8 & 5 \\
\hline & 22 & 20 & 60 & Sup front $g$ & 3.81 & -15.3 & 9 & -6.9 & 5 \\
\hline & 10 & -6 & 48 & Cingulate $\mathrm{g} /$ medial front $\mathrm{g}$ & 4.22 & -16.81 & 8 & -2.6 & 4 \\
\hline & 26 & -10 & 78 & Sup front $g$ & 3.98 & -14.7 & 8 & 8.4 & 4 \\
\hline & 42 & -12 & 48 & Precentral $\mathrm{g}$ /Middle front $\mathrm{g}$ & 3.83 & -14.3 & 8 & 4.7 & 4 \\
\hline & 44 & 58 & -4 & Middle front $\mathrm{g}$ & 3.83 & -17.4 & 9 & -10.6 & 8 \\
\hline & 42 & 34 & 16 & Inf $/$ middle front $\mathrm{g}$ & 3.95 & -16.2 & 8 & -8.7 & 7 \\
\hline & 60 & 28 & 24 & Inf front $\mathrm{g}$ & 3.87 & -15.2 & 8 & & \\
\hline & 12 & 72 & 10 & Medial front $g$ & 3.78 & -14.7 & 9 & -8.4 & 7 \\
\hline
\end{tabular}

Parietal

$\begin{array}{lrlll}\text { IL } & -36 & -18 & 30 & \text { Pre/postcentral g } \\ & -50 & -26 & 20 & \text { Postcentral g/inf par lobule } \\ & -60 & -34 & 54 & \text { Postcentral g/inf par lobule } \\ -6 & -38 & 80 & \text { Postcentral g/sup par lobule } \\ & -42 & -62 & 50 & \text { Inf/sup par lobule } \\ -40 & -70 & 46 & \text { Inf/sup par lobule } \\ & -4 & -82 & 58 & \text { Precuneus } \\ \text { CL } & 4 & -38 & 38 & \text { Cingulate g/Paracentral lobule } \\ & 10 & -40 & 56 & \text { Paracentral lobule/Precuneus } \\ & 32 & -48 & 50 & \text { Inf par lobule } \\ 58 & -48 & 52 & \text { Inf par lobule } \\ 18 & -86 & 60 & \text { Precuneus }\end{array}$

$\begin{array}{lll}4.19 & -13.6 & 9 \\ 3.99 & -15.4 & 9 \\ 4.22 & -17.5 & 8 \\ 4.32 & -16.1 & 9 \\ 4.21 & -18.6 & 9 \\ 4.26 & -18.6 & 9 \\ 4.62 & -22.5 & 9 \\ 3.76 & -16.0 & 8 \\ 4.22 & -17.7 & 9 \\ 4.01 & -16.1 & 9 \\ 3.96 & -16.8 & 8 \\ 4.30 & -18.8 & 9\end{array}$

$\begin{array}{ll}8.5 & 5\end{array}$

5.4

$-5.3$

8.4

$-7.3$

$-7.2$

$-5.0$

$-8.6$

3.2

5.4

4.5

4
3
7
1
6
6
7
5
9
6
5
7
5
5
4
4
4
8
7

Occipital

IL $\quad-14 \quad-64 \quad 14 \quad$ Post cingulate $g$

$3.47-13.5 \quad 8$

$3.6 \quad 3$

Cerebellum

Thalamus

\begin{tabular}{|c|c|c|c|c|c|c|c|c|}
\hline \multirow[t]{2}{*}{ IL } & -10 & -18 & 2 & Thalamus & 3.68 & -15.8 & 7 & 5.9 \\
\hline & -10 & -32 & -2 & Thalamus & 3.55 & -15.1 & 7 & 10.3 \\
\hline $\mathrm{CL}$ & 12 & -12 & 0 & Thalamus & 3.92 & -15.3 & 7 & \\
\hline
\end{tabular}

SPM analysis showing the local maxima after thresholding at $P<0.001$ (coordinates significant at $P<0.05$ corrected for multiple comparisons are indicated in bold). Same conventions as in Table 2 . 

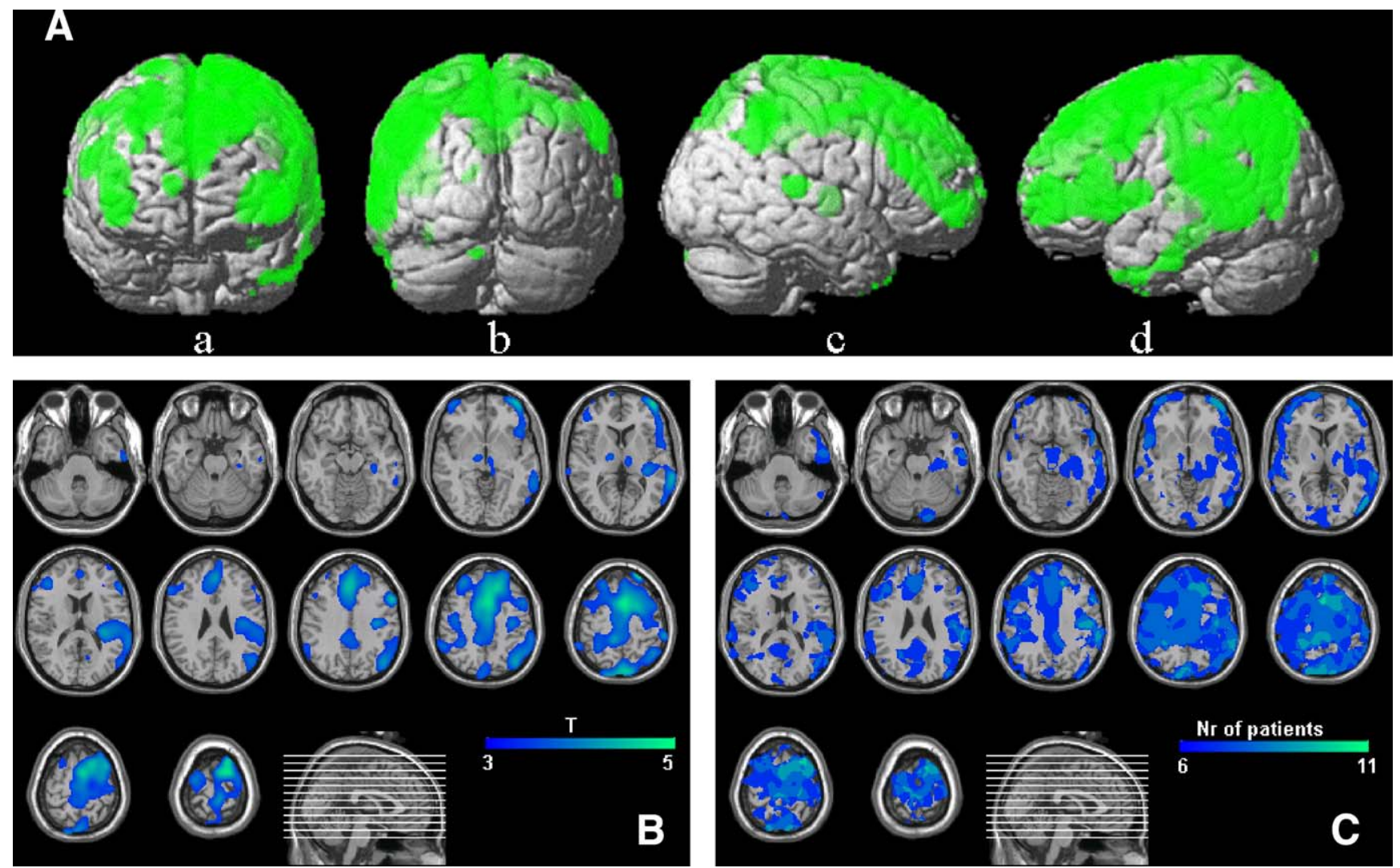

Fig. 3. Interictal FDG-PET metabolism in mTLE-HS. (A) Brain regions with significant interictal hypometabolism (green) (uncorrected $P$ value $<0.001$ ) in 11 patients with HS are shown on a surface rendering of an MRI of the brain. (a) Anterior view, (b) posterior view, (c) contralateral view, (d) ipsilateral view. (B) SPM $t$ map for the analysis of patients versus controls FDG-PET. Hypometabolism is in blue/green. (C) Composite image of FDG-PET hypometabolism (see Materials and methods). Color scale indicates the number of patients (maximum 11) with a given voxel surviving the threshold of $|z|>1$. In both panels B and $\mathrm{C}$, the results were projected on the MRI of a single subject available in SPM2, and right side of the image is ipsilateral to the seizure focus.

signal, that correlated spatially with a decrease in neuronal activity recorded from cortex surrounding the epileptic focus (Schwartz and Bonhoeffer, 2001). Finally, our hypothesis of ictal frontal lobe inhibition is also supported by fMRI experiments suggesting that a sustained negative blood oxygenation level dependent (BOLD) signal is a marker of neuronal deactivation (Stefanovic et al., 2004).

Activation of inhibitory neurons and subsequent activity in inhibitory synapses could both cause increases in neuronal glucose utilization (Jueptner and Weiller, 1995). To explain our findings, we postulate that activation of inhibitory neurons in the temporal lobe contribute to ictal temporal lobe hyperperfusion. We postulate that these inhibitory neurons project to neurons outside the region of epileptic activity causing surround inhibition of neuronal activity. The increased energy demand in activated extratemporal inhibitory synapses would not be able to surpass the greater reduction in energy consumption caused by decreased firing of large areas of inhibited neurons, which is reflected in hypometabolism and hypoperfusion. The greatest hypoperfusion and hypometabolism in the ipsilateral frontal lobe could be explained by the anatomical connections of the two lobes. The most common route of spread of mesial temporal lobe seizures is towards the ipsilateral frontal lobe (Lieb et al., 1991). We speculate, therefore, that surround inhibition is greatest in the pathways of seizure propagation, and that it may play a role in its prevention.

Interictal epileptic activity could explain why the ipsilateral temporal lobe is less hypometabolic than the surrounding tissues.
Patients with mTLE-HS studied with chronically implanted depth electrodes present very frequent, at times continuous spiking, and also electrographical seizures recorded from very small volumes of tissue in the amygdala or hippocampus (Sperling and O'Connor, 1990). Autoradiographic FDG studies, with a spatial resolution of less than $100 \mu \mathrm{m}$ (Goochee et al., 1980), have shown a core of interictal hypermetabolism surrounded by a larger hypometabolic area in animal experiments (Witte et al., 1994). It is possible that the volume of cerebral cortex displaying interictal and subclinical ictal epileptic activity is below the spatial resolution of around 4 $\mathrm{mm}$ of our clinical PET camera, which would not be seen as an area of hypermetabolism, but rather as an area of decreased interictal hypometabolism. This hypothesis is consistent with the observation that the ictal onset zone, as determined with intracranial electrodes, is never the most hypometabolic region (Juhasz et al., 2000).

Prince and Wilder (1967) described the concept of surround inhibition in epilepsy in 1967. The concept has not entered the realm of clinical epileptology since then. Our data provide evidence for the presence of a surround inhibition as a defense mechanism in the brain against the relentless occurrence of seizures in refractory mTLE-HS, for which the patient has to pay a price. Epilepsy surgery is usually conceptualized in terms of the removal of the epileptogenic zone (Rosenow and Lüders, 2001) and outcome with respect to epileptic seizures (Engel et al., 1993). From our findings, we postulate that epilepsy surgery can 

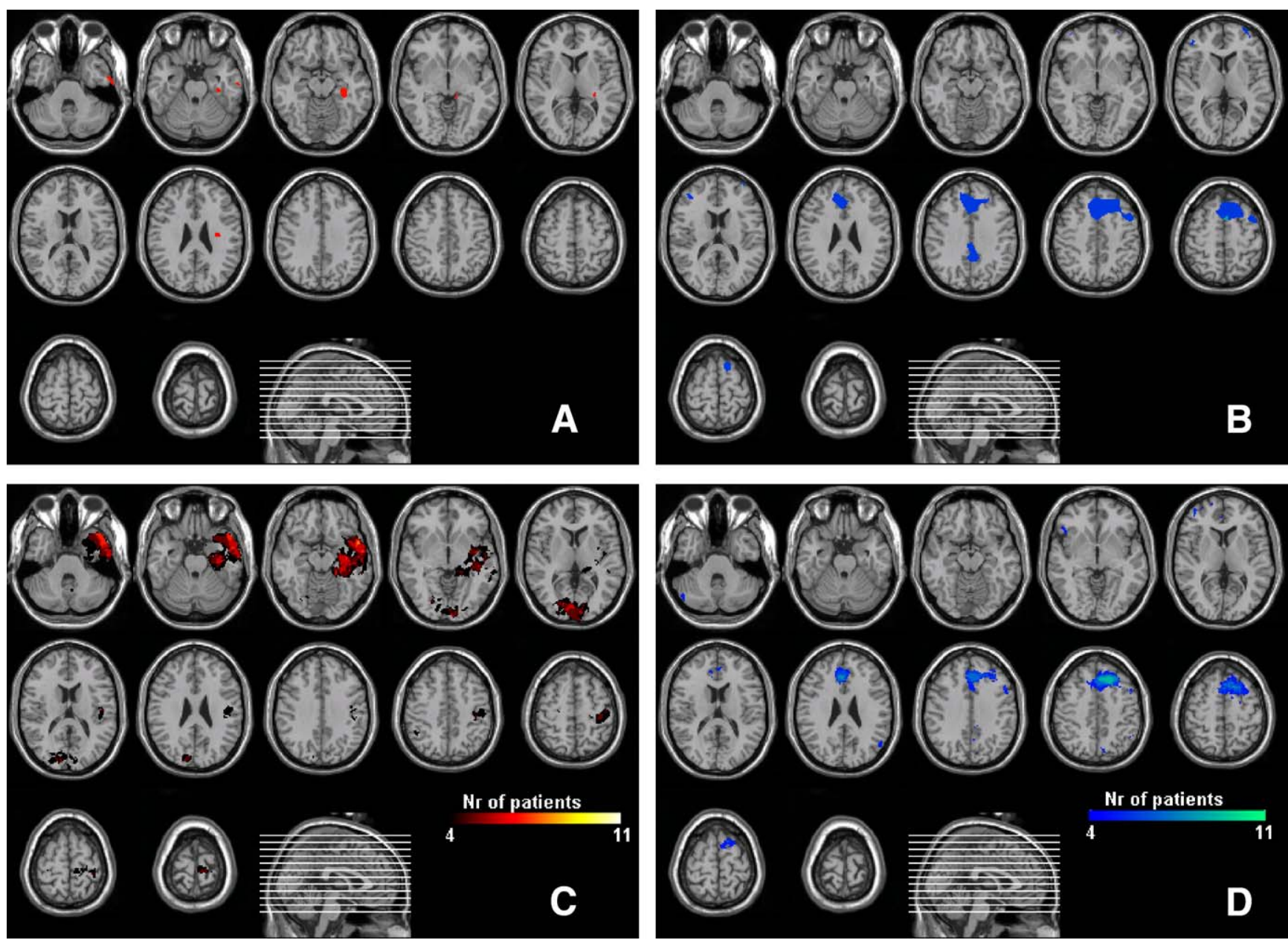

Fig. 4. Composite SPECT-PET Images. Top row: Images showing voxels in which a significant hypometabolism was seen in combination with a significant ictal hyperperfusion (panel A, voxels in red) or with a significant ictal hypoperfusion (panel B, voxels in blue). The results were obtained from a group analysis. Bottom row: Composite images (see Materials and methods) showing the number of patients in a voxel in which hypometabolism (i.e., $z_{\mathrm{PET}}<-1$ ) was seen in combination with ictal hyperperfusion $\left(z_{\mathrm{SPECT}}>1\right)(\mathrm{C})$ or with ictal hypoperfusion $\left(z_{\mathrm{SPECT}}<-1\right)(\mathrm{D})$. The results were obtained from the individual analysis of each patient. The number of patients in each voxel was projected on the MRI of a single subject available in SPM2, and the right side of the image is ipsilateral to the seizure focus. The color scales in panels $\mathrm{C}$ and $\mathrm{D}$ indicate the number of patients (maximum 11).

also be seen as a release of the brakes on the surrounding cortex. Resection of the epileptogenic cortex may disinhibit large regions of the brain which were rendered hypofunctional within the epileptic networks. Preliminary evidence for this has been provided by FDG-PET studies comparing the metabolic activity in synaptically connected structures before and after resection of epileptic mesial temporal sclerosis (Hajek et al., 1994; Joo et al., 2005; Spanaki et al., 2000). This reversion of the functional deficit zones due to the disappearance of the surround inhibition would provide a biological substrate which could partly explain postoperative improvement in cognition (Helmstaedter et al., 2003; Hermann and Seidenberg, 1995), mood (Altshuler et al., 1999; Reuber et al., 2004), and quality of life (Wiebe et al., 2001).

\section{Acknowledgment}

This work was funded by grant Research Fund Katholieke Universiteit Leuven Interdisciplinair Onderzoeksprogramma (IDO) /99/5 and 03/010.

\section{References}

Altshuler, L., Rausch, R., Delrahim, S., Kay, J., Crandall, P., 1999. Temporal lobe epilepsy, temporal lobectomy, and major depression. J. Neuropsychiatry Clin. Neurosci. 11, 436-443.

Baete, K., Nuyts, J., Van Laere, K., Van Paesschen, W., Ceyssens, S., De Ceuninck, L., Gheysens, O., Kelles, A., Van den Eynden, J., Suetens, P., Dupont, P., 2004. Evaluation of anatomy based reconstruction for partial volume correction in brain FDG-PET. NeuroImage 23, 305-317.

Baete, K., Nuyts, J., Van Paesschen, W., Suetens, P., Dupont, P., 2004. Anatomical-based FDG-PET reconstruction for the detection of hypometabolic regions in epilepsy. IEEE Trans. Med. Imag. 23, 510-519.

Blumenfeld, H., McNally, K.A., Vanderhill, S.D., Paige, A.L., Chung, R., Davis, K., Norden, A.D., Stokking, R., Studholme, C., Novotny, E.J. Jr., Zubal, I.G., Spencer, S.S., 2004. Positive and negative network correlations in temporal lobe epilepsy. Cereb. Cortex 14, 892-902.

Blumenfeld, H., Rivera, M., McNally, K.A., Davis, K., Spencer, D.D., Spencer, S.S., 2004. Ictal neocortical slowing in temporal lobe epilepsy. Neurology 63, 1015-1021.

Bonilha, L., Rorden, C., Castellano, G., Cendes, F., Li, L.M., 2005. Voxelbased morphometry of the thalamus in patients with refractory medial temporal lobe epilepsy. NeuroImage 25, 1016-1021.

Bouilleret, V., Valenti, M.P., Hirsch, E., Semah, F., Namer, I.J., 2002. 
Correlation between PET and SISCOM in temporal lobe epilepsy. J. Nucl. Med. 43, 991-998.

Chassoux, F., Semah, F., Bouilleret, V., Landre, E., Devaux, B., Turak, B., Nataf, F., Roux, F.X., 2004. Metabolic changes and electro-clinical patterns in mesio-temporal lobe epilepsy: a correlative study. Brain 127, $164-174$.

Engel, J. Jr., Henry, T.R., Risinger, M.W., Mazziotta, J.C., Sutherling, W.W., Levesque, M.F., Phelps, M.E., 1990. Presurgical evaluation for partial epilepsy: relative contributions of chronic depth-electrode recordings versus FDG-PET and scalp-sphenoidal ictal EEG. Neurology 40, $1670-1677$.

Engel, J. Jr., Van Ness, P.C., Rasmussen, T.B., Ojemann, L.M., 1993. Outcome with respect to epileptic seizures. In: Engel Jr., J. (Ed.), Surgical Treatment of the Epilepsies, (2nd ed.)Raven Press, New York, pp. $609-621$.

Friston, K.J., 1996. Statistical parametric mapping and other analyses of functional imaging data. In: Toga, A.W., Mazziotta, J.C. (Eds.), Brain Mapping. The Methods. Academic Press, San Diego, pp. 363-386.

Gaillard, W.D., Zeffiro, T., Fazilat, S., DeCarli, C., Theodore, W.H., 1996. Effect of valproate on cerebral metabolism and blood flow: an $18 \mathrm{~F}-2-$ deoxyglucose and $15 \mathrm{O}$ water positron emission tomography study. Epilepsia 37, 515-521.

Gold, L., Lauritzen, M., 2002. Neuronal deactivation explains decreased cerebellar blood flow in response to focal cerebral ischemia or suppressed neocortical function. Proc. Natl. Acad. Sci. 99, 7699-7704.

Goochee, C., Rasband, W., Sokoloff, L., 1980. Computerized densitometry and color coding of [14C] deoxyglucose autoradiographs. Ann. Neurol. 7, 359-370.

Hajek, M., Wieser, H.G., Khan, N., Antonini, A., Schrott, P.R., Maguire, P., Beer, H.F., Leenders, K.L., 1994. Preoperative and postoperative glucose consumption in mesiobasal and lateral temporal lobe epilepsy. Neurology 44, 2125-2132.

Helmstaedter, C., Kurthen, M., Lux, S., Reuber, M., Elger, C.E., 2003. Chronic epilepsy and cognition: a longitudinal study in temporal lobe epilepsy. Ann. Neurol. 54, 425-432.

Henry, T.R., Mazziotta, J.C., Engel, J. Jr., Christenson, P.D., Zhang, J.X., Phelps, M.E., Kuhl, D.E., 1990. Quantifying interictal metabolic activity in human temporal lobe epilepsy. J. Cereb. Blood Flow Metab. $10,748-757$

Henry, T.R., Mazziotta, J.C., Engel, J. Jr., 1993. Interictal metabolic anatomy of mesial temporal lobe epilepsy. Arch. Neurol. 50, 582-589.

Hermann, B., Seidenberg, M., 1995. Executive system dysfunction in temporal lobe epilepsy: effects of nociferous cortex versus hippocampal pathology. J. Clin. Exp. Neuropsychol. 17, 809-819.

Hogan, R.E., Kaiboriboon, K., Osman, M., 2004. Composite SISCOM images in mesial temporal lobe epilepsy: technique and illustration of regions of hyperperfusion. Nucl. Med. Commun. 25, 539-545.

Joo, E.Y., Hong, S.B., Han, H.J., Tae, W.S., Kim, J.H., Han, S.J., Seo, D.W., Lee, K.H., Hong, S.C., Lee, M., Kim, S., Kim, B.T., 2005. Postoperative alteration of cerebral glucose metabolism in mesial temporal lobe epilepsy. Brain 128, 1802-1810.

Jueptner, M., Weiller, C., 1995. Review: does measurement of regional cerebral blood flow reflect synaptic activity? Implications for PET and fMRI. NeuroImage, 148-156.

Juhasz, C., Chugani, D.C., Muzik, O., Watson, C., Shah, J., Shah, A., Chugani, H.T., 2000. Is epileptogenic cortex truly hypometabolic on interictal positron emission tomography? Ann. Neurol. $48,88-96$.

Kaiboriboon, K., Bertrand, M.E., Osman, M.M., Hogan, R.E., 2005. Quantitative analysis of cerebral blood flow patterns in mesial temporal lobe epilepsy using composite SISCOM. J. Nucl. Med. 46, 38-43.

Kilpatrick, C., Cook, M., Kaye, A., Murphy, M., Matkovic, Z., 1997. Noninvasive investigations successfully select patients for temporal lobe surgery. J. Neurol., Neurosurg. Psychiatry 63, 327-333.

Lee, H.W., Hong, S.B., Tae, W.S., 2000. Opposite ictal perfusion patterns of subtracted SPECT. Hyperperfusion and hypoperfusion. Brain 123, $2150-2159$.
Lieb, J.P., Dasheiff, R.M., Engel, J. Jr., 1991. Role of the frontal lobes in the propagation of mesial temporal lobe seizures. Epilepsia 32, $822-837$.

Liu, R.S., Lemieux, L., Bell, G.S., Hammers, A., Sisodiya, S.M., Bartlett, P.A., Shorvon, S.D., Sander, J.W., Duncan, J.S., 2003. Progressive neocortical damage in epilepsy. Ann. Neurol. 53, 312-324.

Maes, F., Collignon, A., Vandermeulen, D., Marchal, G., Suetens, P., 1997. Multimodality image registration by maximization of mutual information. IEEE Trans. Med. Imag. 16, 187-198.

Matheja, P., Kuwert, T., Ludemann, P., Weckesser, M., Kellinghaus, C., Schuierer, G., Diehl, B., Ringelstein, E.B., Schober, O., 2001. Temporal hypometabolism at the onset of cryptogenic temporal lobe epilepsy. Eur. J. Nucl. Med. 28, 625-632.

Menzel, C., Grunwald, F., Klemm, E., Ruhlmann, J., Elger, C.E., Biersack, H.J., 1998. Inhibitory effects of mesial temporal partial seizures onto frontal neocortical structures. Acta Neurol. Belg. 98, 327-331.

O’Brien, T.J., So, E.L., Mullan, B.P., Hauser, M.F., Brinkmann, B.H., Bohnen, N.I., Hanson, D., Cascino, G.D., Jack, C.R. Jr., Sharbrough, F.W., 1998. Subtraction ictal SPECT co-registered to MRI improves clinical usefulness of SPECT in localizing the surgical seizure focus Neurology 50, 445-454.

Prince, D.A., Wilder, B.J., 1967. Control mechanisms in cortical epileptogenic foci. "Surround" inhibition. Arch. Neurol. 16, 194-202.

Reuber, M., Andersen, B., Elger, C.E., Helmstaedter, C., 2004. Depression and anxiety before and after temporal lobe epilepsy surgery. Seizure 13, $129-135$.

Rosenow, F., Lüders, H., 2001. Presurgical evaluation of epilepsy. Brain $124,1683-1700$.

Rubin, E., Dhawan, V., Moeller, J.R., Takikawa, S., Labar, D.R., Schaul, N., Barr, W.B., Eidelberg, D., 1995. Cerebral metabolic topography in unilateral temporal lobe epilepsy. Neurology 45, 2212-2223.

Savic, I., Altshuler, L., Baxter, L., Engel, J. Jr., 1997. Pattern of interictal hypometabolism in PET scans with fludeoxyglucose F 18 reflects prior seizure types in patients with mesial temporal lobe seizures. Arch Neurol. 54, 129-136.

Schwartz, T.H., Bonhoeffer, T., 2001. In vivo optical mapping of epileptic foci and surround inhibition in ferret cerebral cortex. Nat. Med. 7, $1063-1067$.

Shin, W.C., Hong, S.B., Tae, W.S., Kim, S.E., 2002. Ictal hyperperfusion patterns according to the progression of temporal lobe seizures. Neurology 58, 373-380.

Spanaki, M.V., Kopylev, L., DeCarli, C., Gaillard, W.D., Liow, K., Fazilat, S., Fazilat, S., Reeves, P., Sato, S., Kufta, C., Theodore, W.H., 2000. Postoperative changes in cerebral metabolism in temporal lobe epilepsy. Arch. Neurol. 57, 1447-1452.

Sperling, M.R., O'Connor, M.J., 1990. Auras and subclinical seizures: characteristics and prognostic significance. Ann. Neurol. 28, $320-328$.

Stefanovic, B., Warnking, J.M., Pike, G.B., 2004. Hemodynamic and metabolic responses to neuronal inhibition. NeuroImage 22, 771-778.

Tae, W.S., Joo, E.Y., Kim, J.H., Han, S.J., Suh, Y.L., Kim, B.T., Hong, S.C., Hong, S.B., 2005. Cerebral perfusion changes in mesial temporal lobe epilepsy: SPM analysis of ictal and interictal SPECT. NeuroImage 24, $101-110$.

Theodore, W.H., 1988. Antiepileptic drugs and cerebral glucose metabolism. Epilepsia 29 (Suppl. 2), S48-S55.

Theodore, W.H., Sato, S., Kufta, C., Balish, M.B., Bromfield, E.B., Leiderman, D.B., 1992. Temporal lobectomy for uncontrolled seizures: the role of positron emission tomography. Ann. Neurol. 32, 789-794.

Van Bogaert, P., Massager, N., Tugendhaft, P., Wikler, D., Damhaut, P., Levivier, M., Brotchi, J., Goldman, S., 2000. Statistical parametric mapping of regional glucose metabolism in mesial temporal lobe epilepsy. NeuroImage 12, 129-138.

Van Leemput, K., Maes, F., Vandermeulen, D., Suetens, P., 1999. Automated model-based tissue classification of MR images of the brain. IEEE Trans. Med. Imag. 18, 897-908. 
Van Paesschen, W., 2004. Ictal SPECT. Epilepsia 45 (Suppl. 4), $35-40$.

Van Paesschen, W., Dupont, P., Van Driel, G., Van Billoen, H., Maes, A., 2003. SPECT perfusion changes during complex partial seizures in patients with hippocampal sclerosis. Brain 126, 1103-1111.

Vanbilloen, H., Dupont, P., Mesotten, L., Mortelmans, L., Verbeke, K., Verbruggen, A., Van Paesschen, W., Van Driel, G., 1999. Simple design for rapid self-injection ictal SPET during aura. Eur. J. Nucl. Med. 26, $1380-1381$

Wiebe, S., Blume, W.T., Girvin, J.P., Eliasziw, M., 2001. A randomized, controlled trial of surgery for temporal-lobe epilepsy. N. Engl. J. Med. $345,311-318$.
Wieser, H.G., 2004. ILAE commission report. Mesial temporal lobe epilepsy with hippocampal sclerosis. Epilepsia 45, 695-714.

Witte, O.W., Bruehl, C., Schlaug, G., Tuxhorn, I., Lahl, R., Villagran, R., Seitz, R.J., 1994. Dynamic changes of focal hypometabolism in relation to epileptic activity. J. Neurol. Sci. 124, 188-197.

Worsley, K.J., Evans, A.C., Marrett, S., Neelin, P., 1992. A threedimensional statistical analysis for $\mathrm{CBF}$ activation studies in human brain. J. Cereb. Blood Flow Metab. 12, 900-918.

Zubal, I.G., Spencer, S.S., Imam, K., Seibyl, J., Smith, E.O., Wisniewski, G., Hoffer, P.B., 1995. Difference images calculated from ictal and interictal technetium-99m-HMPAO SPECT scans of epilepsy. J. Nucl. Med. 36, 684-689. 